\title{
Nutrition capacity development: a practice framework
}

\author{
Roger Shrimpton ${ }^{1, *} \dagger$, Roger Hughes ${ }^{2}$, Elisabetta Recine ${ }^{3}$, John B Mason ${ }^{1}$, \\ David Sanders ${ }^{4}$, Geoffrey C Marks ${ }^{5}$ and Barrie Margetts 6 \\ 'Department of Global Community Health and Behavioural Sciences, Tulane School of Public Health and \\ Tropical Medicine, New Orleans, LA, USA: ${ }^{2}$ Health Professional Education, School of Health Sciences, Bond \\ University, Gold Coast, Queensland, Australia: ${ }^{3}$ Departamento de Nutrição, Observatório de Políticas de \\ Segurança Alimentar e Nutrição, Universidade de Brasília, Brasília, Brazil: ${ }^{4}$ School of Public Health, University \\ of the Western Cape, Bellville, Republic of South Africa: ${ }^{5}$ Nutrition Unit, School of Population Health, University

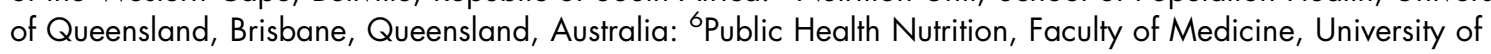 \\ Southampton, Southampton, UK
}

Submitted 9 June 2012: Final revision received 16 March 2013: Accepted 20 March 2013: First published online 7 May 2013

\begin{abstract}
Objective: To outline a framework and a process for assessing the needs for capacity development to achieve nutrition objectives, particularly those targeting maternal and child undernutrition.

Design: Commentary and conceptual framework.

Setting: Low- and middle-income countries.

Result: A global movement to invest in a package of essential nutrition interventions to reduce maternal and child undernutrition in low- and middle-income countries is building momentum. Capacity to act in nutrition is known to be minimal in most low- and middle-income countries, and there is a need for conceptual clarity about capacity development as a strategic construct and the processes required to realise the ability to achieve population nutrition and health objectives. The framework for nutrition capacity development proposed recognises capacity to be determined by a range of factors across at least four levels, including system, organisational, workforce and community levels. This framework provides a scaffolding to guide systematic assessment of capacity development needs which serves to inform strategic planning for capacity development.

Conclusions: Capacity development is a critical prerequisite for achieving nutrition and health objectives, but is currently constrained by ambiguous and superficial conceptualisations of what capacity development involves and how it can be realised. The current paper provides a framework to assist this conceptualisation, encourage debate and ongoing refinement, and progress capacity development efforts.
\end{abstract}

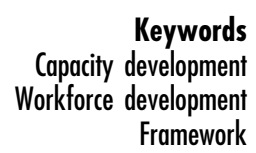

A consensus on the need to act in nutrition has been building for over a decade, but how to create the capacity to do this and what capacity is needed are still far from clear. A call for action was made at the turn of the millennium when it was realised that despite considerable economic development in the last two decades, there had been little or no improvement in maternal and child undernutrition rates in most developing countries, with at least a half of these vulnerable population groups still so affected $^{(1)}$. Despite the existence of known interventions, nutrition had been largely sidelined in national poverty reduction and development programmes. Recognition that the lack of improvement in maternal and child undernutrition threatened the achievement of many of

$\dagger$ Correspondence address: Urbanização Zona Alta, Lote 1, Apt 3D, 8700-270, Olhão, Portugal. the Millennium Development Goals ${ }^{(2)}$ led to the agreement to promote the repositioning of nutrition as central for development and that it should be mainstreamed in national development plans ${ }^{(3)}$.

The Lancet Nutrition Series (LNS) ${ }^{(4)}$ provided an important impetus to this repositioning process. The series confirmed that development funding for maternal and child undernutrition has been far too small ${ }^{(5)}$, especially considering the negative consequences it brings in terms of mortality, morbidity ${ }^{(6)}$ and human capital development ${ }^{(7)}$, and that the LNS package of interventions could prevent at least a quarter of the deaths of children under 36 months of age and reduce the prevalence of stunting in the countries most affected by about a third in the short term ${ }^{(8)}$. The momentum to act in nutrition is further gathering support through a process called SUN (Scaling Up Nutrition) ${ }^{(9)}$, which calls for 
development partners to help in scaling up a further refined and costed LNS package. By the end of 2012 over a hundred development partners had signed up to the SUN Movement, and of the thirty-three countries that had joined twenty-nine had established high-level coordination mechanisms and twenty had developed updated and budgeted national nutrition plans ${ }^{(10)}$.

Evidence from the WHO-led Landscape Analysis Country Assessments carried out in many low- and middleincome countries (LMIC) over the last 5 years indicates that the capacity to act in nutrition is very often quite limited, both at national and district levels ${ }^{(11)}$. Improving nutrition capacity at all levels of the health system by producing more master's graduates down to improving health professionals' in-service training is a common recommendation of Landscape Analysis reports. However, very few of these countries have academic centres that provide formal nutrition training. So how to develop this 'capacity' is obviously a challenge.

Before trying to strengthen nutrition capacity in LMIC, there is a need to have a common understanding of the sort of capacities needed, including an understanding of what capacity exists and what capacity must be developed, as well as what are the challenges, the limitations and the opportunities for doing this. Based on such an assessment a capacity development plan could be established for a country with much greater certainty that all bases are covered. Similarly, if other countries in the same geographic region were assessed using the same approach, it would facilitate working out regional mechanisms to support nutrition development in a collaborative fashion across the region.

The purpose of the current paper is to outline a conceptual framework for capacity development to facilitate a more systematic approach to assessing the need for nutrition capacity development in LMIC, especially those most affected by maternal and child undernutrition.

\section{What do we mean by capacity?}

Capacity, most simply defined, is the ability to carry out stated objectives ${ }^{(12)}$. Capacity development and capacity building, terms often used interchangeably, essentially refer to the process by which individuals, groups, organisations and societies increase their ability to perform, solve problems, define objectives, understand and deal with development needs to achieve objectives in a sustainable manner ${ }^{(13)}$.

The capacity to act in nutrition has been signalled as a critical element limiting the large-scale implementation of nutrition programmes for several decades. The need for a more balanced approach, not only looking at the 'what to do' but also looking at the 'how to do' and 'who to do it', has been a recurrent theme among nutritionists concerned with the application of nutrition science ${ }^{(14-18)}$.
While other reviews prior to the LNS interventions paper ${ }^{(8)}$ confirm that the 'what' of undernutrition is reasonably well established ${ }^{(19,20)}$, and a considerable body of experience exists on working out the 'how' in various developmental settings across the globe ${ }^{(21-23)}$, the capacity to act or to implement such activities at scale in the LMIC most affected has been found to be lacking ${ }^{(24)}$ and the capacity to train people to manage and implement nutrition programmes in such LMIC to be virtually non-existent ${ }^{(25)}$.

\section{Building on earlier approaches to developing nutrition capacity}

Workforce development has been a central focus of earlier approaches to capacity development. Efforts to establish a framework and strategy for developing nutrition capacity in LMIC began two decades ago at a meeting in Manila hosted by the United Nations University (UNU) and the International Union of Nutritional Sciences (IUNS) ${ }^{(26)}$. The focus of these early efforts was on building the capacity for advanced training in food and nutrition, and research capacity. The concept of a national training pyramid was agreed at the Manila meeting with three types of functional categories: (i) policy/decision makers; (ii) researchers/planners/ trainers; and (iii) programme implementers. It was also recognised that requirements for a critical mass of professionals made it imperative that scarce resources should be concentrated in a few highly selected academic or research institutions. The UN System Standing Committee on Nutrition's working group on capacity development in food and nutrition, created in 2000 with UNU and IUNS as chairs, established regional task forces for Asia, Africa, the Middle East, Central and Eastern Europe and Latin America. Reports from the UN System Standing Committee on Nutrition's Annual Sessions show that the focus of these efforts remained on advanced training and research in universities. At the last session in 2008 it was reported that retaining young faculty members had become increasingly difficult due to low salaries, deteriorating infrastructure, inadequate resources to conduct research and increased teaching obligations ${ }^{(27)}$. One of the main obstacles reported by the task forces in Africa was the lack of enthusiasm for 'capacity building' among donor agencies ${ }^{(28)}$.

Experience in the health sector more generally has shown that training of health professionals is not in itself a panacea, and unless this is rooted in an appropriate understanding of the health system, it is unlikely to be fruitful $^{(29)}$. A recent analysis of the capacity for training in public health nutrition in West Africa ${ }^{(30)}$ noted a lack of attention to the societal dimensions of capacity development including governance issues. Although most African countries have insufficient nutrition capacity, countries 
Table 1 Dimensions of a nutrition capacity assessment framework

\begin{tabular}{|c|c|c|}
\hline Level & Description/Key elements & Examples \\
\hline System & $\begin{array}{l}\text { Legal frameworks } \\
\text { Social-cultural-economic factors } \\
\text { Sectoral policies } \\
\text { Government structures: departments, portfolios }\end{array}$ & $\begin{array}{l}\text { Human rights instruments } \\
\text { National action plans for nutrition } \\
\text { Health system structure and funding } \\
\text { Health targets and priorities } \\
\text { Workforce quality assurance systems (e.g. registration systems) } \\
\text { Agricultural and export policies and practices } \\
\text { Educational system }\end{array}$ \\
\hline Organisational & $\begin{array}{l}\text { National coordination mechanisms } \\
\text { Workforce size, structure and organisation }\end{array}$ & $\begin{array}{l}\text { University nutrition departments, programmes and faculty } \\
\text { Number of nutrition personnel relative to population/need, } \\
\text { location, distribution, management support and co-location } \\
\text { with other disciplines }\end{array}$ \\
\hline & Access to information systems & $\begin{array}{l}\text { Availability of public health intelligence infrastructure and } \\
\text { information }\end{array}$ \\
\hline & $\begin{array}{l}\text { Sector-specific interventions } \\
\text { Tertiary education institutions }\end{array}$ & Existing national or provincial nutrition interventions \\
\hline Workforce & $\begin{array}{l}\text { Competencies (knowledge, attitudes and skills } \\
\text { required to perform in workplace) } \\
\text { Workforce preparation }\end{array}$ & $\begin{array}{l}\text { Different workforce tiers: nutritionists and non-nutritionists } \\
\text { Continued professional development } \\
\text { Performance review and evaluations } \\
\text { Professional standards and networks } \\
\text { Training pathways/system }\end{array}$ \\
\hline Community & $\begin{array}{l}\text { Community organisations } \\
\text { Social capital } \\
\text { Leadership }\end{array}$ & $\begin{array}{l}\text { Community-led health services or nutrition programmes } \\
\text { Resources accessed by communities to address nutrition issues } \\
\text { Social networks and community organisations (e.g. breast- } \\
\text { feeding mothers groups) } \\
\text { Facilitation and mobilisation }\end{array}$ \\
\hline
\end{tabular}

like Nigeria and Ghana have an abundance of graduates, but they are not employed in nutrition programmes. Elsewhere countries like Thailand and Indonesia, which successfully eliminated severe malnutrition using community-based nutrition programmes, are now threatened by escalating problems of overweight/obesity linked with diabetes and high blood pressure albeit with little or no primary health-care response capacity ${ }^{(31,32)}$. Recent decentralisation of governance to district level in Indonesia caused problems because nutrition professionals capable of developing local nutrition plans are rarely employed in the health service at that level ${ }^{(33)}$. Workforce development, while central to nutrition capacity development assessment and strategic planning, is not in itself adequate and a broader, more conceptual approach is needed.

\section{A framework for nutrition capacity assessment and strategic planning}

This framework has been informed by the analytical framework used for conducting the Landscape Analysis ${ }^{(34)}$ which includes indicators for assessing the ability to act, which is the capacity to do things, as well as those for willingness to act, which is more related to the existence of policies as well as budget allocations and other factors that enable staff to act. The proposed framework has four levels, including system, organisational, workforce and community levels, as shown in Table 1 . While the system level concerns the policy dimensions of capacity, the organisational-, workforce- and community-level dimensions concern factors which more directly influence the ability to act. These levels are in agreement with those proposed by LaFond et al. ${ }^{(13)}$ for mapping capacity in the health sector. It is realised that nutrition capacity has to stretch beyond the health sector alone however, as is discussed further in the text below.

\section{The system level}

This level refers to the broader social, cultural, economic and political 'environment' that influences how nutrition capacity develops and has its operational effects, including legal frameworks and supporting policies. Of particular relevance to nutrition are the state commitments to various human rights instruments. For example, the 1979 Convention on the Elimination of All Forms of Discrimination Against Women specifies in Article 12 a right to adequate nutrition during pregnancy and lactation ${ }^{(35)}$. Other examples include legislation on a code of marketing of breast milk substitutes, as well as on salt iodisation, all recommended by the World Health Assembly. National nutrition plans provide system-level policy mandates for action on nutrition, and it is worth noting here that the World Health Assembly has now urged all member states to put into practice a Comprehensive Implementation Plan to improve maternal and child nutrition ${ }^{(36)}$. The SUN Movement is essentially multi-sectoral and advocates that national nutrition plans be developed in the context of an overarching national strategy for food, health and nutrition security ${ }^{(9)}$.

Efforts to improve national nutrition capacity need to be equated with the development of a set of professional competencies as well as establishing systems to ensure that those employed to manage such processes are suitably 
qualified, and vice versa ${ }^{(37)}$. These include workforce quality assurance rules and regulations that prescribe requirements for nutrition professionals. This will include accreditation requirements for training programmes or individuals, and regulations from public administrations specifying staffing profiles for particular services (e.g. school meal services).

\section{Organisational level}

This level considers the nature of organisations working in nutrition-related areas, including government service delivery sectors, non-governmental organisations, as well as educational and training institutions. Included are factors that develop, support and enable the workforce to be effective, ranging from workforce preparation, leadership and resources available, to human resource management systems and the workplace culture that the nutrition workforce is embedded in. This level is critically important in enabling the nutrition-related workforce to effectively and efficiently perform workforce functions and deliver nutrition interventions ${ }^{(38)}$.

National-level coordination is important for multisectoral nutrition programmes. The SUN Movement framework for action $^{(9)}$ proposes 'three ones', namely: one agreed framework that provides the basis for coordinating the work of all partners; one national coordinating authority with a broad multi-sectoral mandate; and one agreed national monitoring and evaluation plan. Previous experience with multi-sectoral nutrition programmes ${ }^{(39)}$ certainly suggests that a high-level coordination forum is needed that can periodically agree to and sign off on the national nutrition plan and budget.

Improved nutrition programme effectiveness requires that appropriate nutrition indicators be included in the various sectoral information systems and be used in periodic review and decision making at all levels. This should include monthly programme monitoring by programme managers and supervisors at district level through to programme evaluation every 5 years at the national level, linking to national research institutions as appropriate.

Tertiary education institutions are key organisationallevel determinants of nutrition capacity. The pre-service training of professionals, not only of nutritionists, but also nurses and midwives, as well as agricultural extension workers and teachers, must all have appropriate nutrition content. Furthermore, sectoral training institutes that provide in-service training can potentially be used to 're-train' the existing the workforce, especially in relation the double burden of malnutrition for instance.

\section{Workforce level}

This level includes the knowledge, skills and attitudes required to perform the required work (competencies) of those involved in carrying out nutrition-related work, as well as the materials and job-aids needed to be effective for their various responsibilities. The competencies that are required by staff (some of which might be called 'nutritionists' and others not) at different levels of the nutrition system need to be equated with the appropriate models of service delivery for ensuring the improved nutritional outcomes that are desired (including prevention of undernutrition and overnutrition, treatment of macro- and micronutrient deficiencies as well as nutritional rehabilitation).

Some of these are obviously going to be sector specific and will be reflected in programme budgets and human resources dedicated to delivering these nutrition interventions. The SUN Movement is committed to a multi-sectoral approach, with direct 'nutrition specific' interventions being delivered predominantly through the health sector, in addition to broader more indirect 'nutrition sensitive' interventions delivered through the agriculture, education and water and sanitation sectors ${ }^{(9)}$. Nutrition-sensitive interventions may vary considerably ${ }^{(40)}$, from hand washing and toilet construction to food production and cash transfers, for example. All of these sectoral activities will require their own management information systems, as well as logistic support for delivering supplies as necessary, all of which will be linked to regular supervisory and periodic review procedures.

Workforce preparation and continuing professional development are central platforms at this workforce level. A competency framework has been proposed in order to orient the development of effective public health nutrition practice at the various levels of the health service ${ }^{(41)}$. The building blocks of such a framework include different components/determinants of capacity such as leadership, nutrition status assessment and intervention management, for example. Many different types of nutrition professionals can be trained to plan and manage the different types of interventions. In an LMIC setting where nutrition capacity assessments are to be carried out with a view to accelerating the reduction of maternal and child undernutrition, the immediate focus is on the need to develop and strengthen public health nutrition workforce capacity by empowering practitioners with a specific and specialised remit to lead the delivery of public health nutrition core functions.

Perhaps the greatest challenge is providing guidance to the many health professionals at the periphery of health services who deliver nutrition-specific interventions without a technical preparation, and especially to enable them to build capacity at the community level. In most LMIC developing the workforce and community capacity to act on nutrition quickly is going to be an enormous challenge. Using the ratios proposed by the UNU/IUNS Manila meeting, it has been suggested that in West Africa alone, with a population of 300 million, between 600 and 3000 new bachelor-level graduates in nutrition would be needed each year to fill positions as programme implementers/managers ${ }^{(42)}$. Even the lower number is five times greater than current capacity. It should also be borne in mind that most of those trained will be skilled more as researchers than programme managers. Furthermore, the 
IUNS/UNU calculations did not include the numbers of 'non-nutrition' workers who need nutrition training.

Developing the workforce to act in nutrition at such a scale will obviously require new and innovative methods. Waiting to train enough master- and bachelor-level graduates, so that they can in turn help create the capacity needed with other workers (in health and other sectors) or for community mobilisation, will require considerable investments over several decades and indeed may not even work. In the meantime and in order to meet the challenge and provide such human resources now, people must be able to train 'on the job', potentially through a mixture of distance learning and periodic coming together with tutors and mentors. Such innovative models have been developed which provide access to masterlevel public health education through distance education for health professionals from more than twenty African countries while they remain in post ${ }^{(43)}$. A proposed Public Nutrition Virtual University ${ }^{(44)}$, although still waiting funding, aims to establish a 'virtual faculty' that follows a common syllabus/approach, building on existing institutions in LMIC that would issue the certificates. The Public Nutrition Virtual University would provide these institutions with a flexible resource of training, mentoring and support from external institutions while the local capacity is strengthened. Such an approach would also need to include supporting a cascade process to develop capacity down to the village level. In parallel, other efforts can also be developed for supporting professionals through social networks that facilitate discussion and exchange of experiences as well as providing simple tools for updating through self-learning modules. An example is provided by the 'Nutrition Network' of the Brazilian National Health System ${ }^{(45)}$.

\section{Community level}

This level focuses on, and acknowledges the importance of, community development in overall nutrition capacity development. Efforts to strengthen the capacity to improve nutrition must recognise the need to actively involve 'beneficiaries' in the processes to improve nutrition and so progressively realise their rights ${ }^{(46)}$. Community participation is a continuum that can be built gradually to move from the traditional 'top-down', welfare and passive recipient type of participation towards active 'bottom-up' management of community resources to achieve better nutrition outcomes for the whole community ${ }^{(47)}$.

The essential elements of successful community-based nutrition programmes include community ownership, adequate population coverage, targeting, and central support for supplies and training ${ }^{(23)}$. Community-based initiatives are typically linked to a village organisational structure, such as the village health committee or a mothers' group, and an external service delivery worker 'facilitates' the work of a community 'mobiliser' that brings mothers together for the pursuit of the agreed objectives. The intensity of effort needed to achieve impact on young child growth requires ratios of not more than twenty mobilisers per facilitator and not more than twenty households per mobiliser. So capacity in this instance goes beyond the usual notion of employees of government and non-governmental organisations to include a range of roles for members of the community.

\section{Nutrition capacity needs assessment process}

The proposed process for progressing nutrition capacity development follows the traditional action research cycle, or 'triple A' process ${ }^{(48)}$. Experience has shown that capacity development is best structured as part of a continuous learning and change process that includes empowerment of individuals and organisations, and requires systematic approaches ${ }^{(49)}$. Frequently capacity building efforts translate into little more than a one-off training ${ }^{(28)}$ which, unless it is part of a broader initiative, is likely to be merely palliative and not lead to sustained improvements.

As a result, nutrition capacity assessment is best seen as part of a capacity building process which involves the principal actors so that they can become owners of the process and products. The process used in developing the Landscape Analysis is a suitable one to follow in this regard, and the Landscape Assessment Tools ${ }^{(50)}$ can be adapted as necessary to allow a team of national assessors to collect information on the various levels of the Capacity Assessment Framework. Having collected this information, the team can carry out a joint analysis of the situation and make its recommendations for action to strengthen nutrition capacity.

\section{Nutrition capacity development planning}

Plans for strengthening nutrition capacity must include short-, medium- and long-term perspectives. Although concentrating in the short term on creating a workforce capacity that will enable the scaling up of nutrition action to tackle maternal and child undernutrition, the plan should also contemplate the organisational and system issues that need to be resolved over the medium and long terms. In addition to which, the plan must also consider how to tackle the double burden of malnutrition at least in the medium term.

Not realising and planning for investments on all four levels of the assessment framework endangers the whole idea of scaling up nutrition. As the evaluation of UNICEF support to community-based growth monitoring during the 1980s and 1990s revealed, insufficient attention was paid to the human, financial and organisational resources needed to start and maintain such efforts ${ }^{(51)}$. This showed that systems-based workforce development must involve: (i) understanding the work needed; (ii) identifying who can do this work and at what level (including quantification); 
(iii) training a workforce for these roles; (iv) supporting this workforce; and (v) ensuring workforce quality.

The final product of the needs assessment should be a strategic plan that embraces all levels of the capacity development framework. It may spell out who will be trained, the roles, job descriptions and funding provisions. But it should also consider opportunities for strengthening system- and organisational-level capacity in ways that provide support for nutrition agendas and action and are likely to make the workforce more effective. The plan should consider training for all categories of worker who can influence nutritional health, including non-nutrition staff such as nurses who carry out nutritionrelated activities. Competencies should be listed and syllabuses described. Although focusing on public health nutrition, the capacity development activities proposed should also give recognition to other nutrition-related competencies needed in the health system, from diet therapy through to institutional catering, as well as of public nutritionists in other sectors.

The means for developing the capacity required must also be spelt out, with provision of numbers that would be sent for higher training either abroad or locally, as well as how many would be trained locally on the job by distance learning through Public Nutrition Virtual University-type arrangements and how many would be trained through cascade training, be it by external trainers to begin with and/or by local trainers once they have been trained. For all of these the budgetary sources should be indicated, or at least show what needs to be funded. In order to ensure all of this there is a need to create mechanisms for generating political commitment among the areas of government concerned, especially in the health and education sectors as well as universities and professional organisations ${ }^{(52)}$.

\section{Conclusions}

The renewed momentum to act in nutrition among development partners means a new and increased interest in nutrition capacity development in LMIC. Before strengthening nutrition capacity in these countries, there is a need to have a common understanding of the sort of capacity needed: i.e. what capacity exists and what capacity must be developed, as well as what the challenges, the limitations and the opportunities are for doing this. A framework is proposed to help shape the capacity needs assessment which covers four dimensions of capacity development: system, organisational, workforce and community levels. This approach will give an outcome tailored to the current capacity, opportunities and needs for each country. If capacity building efforts only consider the workforce level, without considering the community, organisational and system-wide dimensions, the effectiveness and the sustainability of any such efforts are likely to be short lived. In addition, capacity development initiatives must envisage the double burden of malnutrition, since most LMIC are already experiencing the nutrition transition with overnutrition growing faster than undernutrition decreases.

\section{Acknowledgements}

Sources of funding: This research received no specific grant from any funding agency in the public, commercial or not-for-profit sectors. Conflicts of interest: There are no conflicts of interest reported by any of the authors. Ethics: Ethical was approval not required. Authors' contributions: All authors contributed during a one-day 'face-to-face' discussion of the topic (Capacity Building in Public Health Nutrition), subsequent to which R.S. did a first draft which all authors made comments on. R.S. then prepared the final version which all authors have seen and agreed to.

\section{References}

1. Gillespie S, McLachlan M \& Shrimpton R (2003) Combating Malnutrition: Time to Act. Washington, DC: The World Bank.

2. United Nations System Standing Committee on Nutrition (2004) 5th Report on the World Nutrition Situation: Nutrition for Improved Development Outcomes. Geneva: UNSCN.

3. Shekar M, Heaver R \& Yi-Kyoung L (2006) Repositioning Nutrition as Central to Development: A Strategy for LargeScale Action. Directions in Development. Washington, DC: The World Bank.

4. Horton R (2008) Maternal and child undernutrition: an urgent opportunity. Lancet 371, 179.

5. Morris SS, Cogill B, Uauy R et al., for the Maternal and Child Undernutrition Study Group (2008) Effective international action against undernutrition: why has it proven so difficult and what can be done to accelerate progress? Lancet $\mathbf{3 7 1}$, 608-621.

6. Black RE, Allen LH, Bhutta ZA et al., for the Maternal and Child Undernutrition Study Group (2008) Maternal and child undernutrition: global and regional exposures and health consequences. Lancet 371, 243-260.

7. Victora CG, Adair L, Fall C et al., for the Maternal and Child Undernutrition Study Group (2008) Maternal and child undernutrition: consequences for adult health and human capital. Lancet 371, 340-357.

8. Bhutta ZA, Ahmad T, Black RE et al., for the Maternal and Child Undernutrition Study Group (2008) What works? Interventions for maternal and child undernutrition and survival. Lancet 371, 417-440.

9. Nabarro D (2010) Introducing the Policy Brief- 'Scaling up Nutrition': A Framework for Action. New York: UN.

10. Scaling Up Nutrition (2013) SUN Movement Brief. New York: UNSCN; available at http://scalingupnutrition.org/ wp-content/uploads/2013/01/SUN-Movement-Brief_January2013.pdf

11. Nishida C, Shrimpton R \& Darnton-Hill I (2009) Landscape analysis on countries' readiness to accelerate action in nutrition. SCN News 37, 4-9.

12. Goodman RM, Speers MA, McLeray K et al. (1998) Identifying and defining the dimensions of community capacity to provide to provide a basis for measurement. Health Educ Behav 25, 258-278. 
13. LaFond AK, Brown L \& Macintyre K (2002) Mapping capacity in the health sector: a conceptual framework. Int J Health Plann Manage 17, 3-22.

14. Berg A (1992) Sliding toward nutrition malpractice: time to reconsider and redeploy. Am J Clin Nutr 57, 3-7.

15. Brown KH \& Dewey KG (1993) Slipping to scapegoating in international nutrition. Am J Clin Nutr 57, 89-91.

16. Jonsson U (1993) The global embarrassment of malnutrition and the role of nutrition engineers. Am J Clin Nutr 58, 579-580.

17. Chopra M \& Sanders D (2000) Asking 'how?' rather than 'what, why, where, and who?' BMJ 321, 832

18. Heikens GT, Amadi BC, Manary M et al. (2008) Nutrition interventions need improved operational capacity. Lancet 371, 181-182.

19. Gillespie S \& Mason J (1991) Nutrition-relevant Actions: Some Experiences from the Eighties and Lessons for the Nineties. Nutrition Policy Paper no. 10. Geneva: UNSCN.

20. Allen L \& Gillespie S (2001) What Works? A Review of the Efficacy and Effectiveness of Nutrition Interventions. Nutrition Policy Paper no. 19. Geneva: UNSCN.

21. Jennings J, Gillespie S, Mason J et al. (1990) Managing Successful Nutrition Programmes. Nutrition Policy Paper no. 8. Geneva: UNSCN.

22. Gillespie S, Mason J \& Martorell R (1996) How Nutrition Improves. Nutrition Policy Paper no. 15. Geneva: UNSCN.

23. Mason JB, Sanders D, Musgrove P et al. (2006) Community health and nutrition programs. In Disease Control Priorities in Developing Countries, 2nd ed., pp. 1053-1074 [DT Jamison, JG Breman, AR Measham et al., editors]. Washington, DC: The World Bank.

24. Mason J, Hunt J, Parker D et al. (1999) Investing in child nutrition in Asia. Asian Dev Rev 17, 1-32.

25. Bryce J, Coitinho D, Darnton-Hill I et al., for the Maternal and Child Undernutrition Study Group (2008) Maternal and child undernutrition: effective action and the national level. Lancet 371, 510-526.

26. United Nations University \& International Union of Nutritional Sciences (1997) Executive summary of the workshop on institution-building for research and advanced training in food and nutrition in developing countries in Manilla, Philippines. Food Nutr Bull 18, 103-109.

27. United Nations System Standing Committee on Nutrition (2008) Report of the Standing Committee on Nutrition at its Thirty-Fifth Session. Geneva: UNSCN.

28. Pepping F (2007) UNU/IUNS nutrition capacity building efforts in Africa. SCN News 33, 39-42.

29. Potter C \& Brough R (2004) Systemic capacity building: a hierarchy of needs. Health Policy Plann 19, 336-345.

30. Pepping F (2010) The current capacity for training in public health in West Africa. Glob Public Health 5, Suppl. 1, S20-S41.

31. Sranacharoenpong K \& Hanning RM (2011) Developing a diabetes prevention education programme for community health-care workers in Thailand: formative findings. Prim Health Care Res Dev 12, 357-369.

32. Shrimpton R (2012) The Double Burden of Malnutrition in Indonesia. Indonesia Health Sector Review Series. Jakarta: The World Bank.

33. Friedman J, Heywood PF, Marks G et al. (2006) Health Sector Decentralization and Indonesia's Nutrition Programs: Opportunities and Challenges. Report no. 39690-IND. Washington, DC: The World Bank.

34. Chopra M, Pelletier D, Wilten C et al. (2009) Assessing countries readiness: methodology for in-depth country assessments. SCN News 37, 17-22.
35. United Nations (1979) The Convention on the Elimination of All Forms of Discrimination Against Women (CEDAW). New York: UN General Assembly.

36. World Health Organization (2012) 65th World Health Assembly Agenda Item 13. Maternal Infant and Young Child Nutrition. Geneva: WHO.

37. Hughes R (2004) Competencies for effective public health nutrition practice: a developing consensus. Public Health Nutr 7, 683-691

38. Baillie E, Bjarnholt C, Gruber M et al. (2009) A capacity building conceptual framework for public health nutrition practice. Public Health Nutr 12, 1031-1038.

39. Nishida C, Mutru T, Imperial Laue R (2003) Strategies for effective and sustainable national nutrition plans and policies. In Forum of Nutrition. vol. 56: Modern Aspects of Nutrition, Present Knowledge and Future Perspectives, pp. 264-266 [I Elmadfa, E Anklam and JS Konig, editors]. Basel: Karger.

40. Mucha N (2012) Implementing Nutrition-Sensitive Development: Reaching Consensus. Briefing Paper no. 10. Washington, DC: Bread for the World Institute.

41. Hughes R, Shrimpton R, Recine E et al. (2012) Empowering our profession. World Nutr 3, 33-54; available at http:// www.wphna.org/2012_feb_wn3_competencies.htm

42. Brown KH, McLachlan M, Cardoso P et al. (2010) Strengthening Public Health Nutrition Research and Training Capacities in West Africa: Report of a Planning Workshop Convened in Dakar, Senegal, 26-28 March 2009. New York: Helen Keller International.

43. Alexander L, Igumbor EU \& Sanders D (2009) Building capacity without disrupting health services: public health education for Africa through distance learning. Hum Resour Health 7, 28.

44. Mason J (2011) Public Nutrition Virtual University (PNVU) http://www.tulane.edu/ internut/PNVU/PNVU\%20Home. html (accessed April 2013).

45. Ministério da Saúde (2012) Redenutri: A rede de nutrição do sistema única de saúde. Brasília: Ministerio da Saude; available at http://ecos-redenutri.bvs.br/tiki-index.php? page $=$ sobre

46. Gillespie S (2001) Strengthening Capacity to Improve Nutrition. FCND Discussion Paper no. 106. Washington, DC: IFPRI

47. Shrimpton R (1995) Community participation in food and nutrition programs: an analysis of governmental experiences. In Child Growth and Nutrition in Developing Countries, pp. 243-261 [P Pinstrup-Andersen, D Pelletier and $\mathrm{H}$ Alderman, editors]. Ithaca, NY: Cornell University Press.

48. UNICEF (1990) Strategy for Improved Nutrition of Children and Women in Developing Countries. New York: UNICEF.

49. United Nations Development Programme (1997) Capacity Development. Management and Development and Governance Division. Technical Advisory Paper no. 2. New York: UNDP.

50. World Health Organization (2012) Landscape Analysis on Countries' Readiness to Accelerate Action in Nutrition: Country Assessment Tools. Geneva: WHO.

51. Pearson R (1995) Thematic Evaluation of UNICEF Support to Growth Monitoring. Evaluation \& Research Working Paper Series no. 2. New York: UNICEF.

52. Heaver R (2005) Strengthening Country Commitment to Human Development: Lessons from Nutrition. Directions in Development. Washington, DC: The World Bank. 